\title{
ALLOYS-BY-DESIGN: TOWARDS OPTIMIZATION OF COMPOSITIONS OF NICKEL-BASED SUPERALLOYS
}

\author{
Roger C. Reed ${ }^{1}$, Alessandro Mottura ${ }^{2}$, David J. Crudden ${ }^{1}$ \\ ${ }^{1}$ Department of Materials, University of Oxford, Parks Road, Oxford, OX1 3PJ, UK \\ ${ }^{2}$ School of Metallurgy and Materials, University of Birmingham, Edgbaston, Birmingham B15 2TT, UK
}

Keywords: alloy development, nickel-superalloy, materials genome

\begin{abstract}
The composition of a range of different nickel-based superalloys are isolated using theory-based computational modeling, termed 'Alloys-by-Design' methods. Each alloy has been designed with different applications in mind. A polycrystalline alloy is designed for turbine disc applications, here emphasis is placed on the composition dependence of strength. Examples of the design tradeoffs faced when increasing alloy strength are presented. Three new single crystal alloy compositions are designed. They are (i) a second generation type alloy with a reduced level of rhenium, (ii) a creep resistant alloy designed for high performance jet applications and (iii) a low cost corrosion resistant alloy designed specifically for industrial gas turbine applications. In each case the newly designed alloys have been manufactured. Design critical properties are measured and compared with modeling predictions to test the accuracy of this alloy design approach.
\end{abstract}

\section{Introduction}

Traditionally, our industry has relied upon a relatively small number of superalloy compositions. Why? Due to an emphasis on trial-and-error procedures it has been usual to proceed via campaigns involving the melting of between 10 and 100 heats, followed by their ranking using experimental testing. Rules-ofthumb and prior experience have been fed in at an early stage, to decide upon the compositions to be tested. This implies an empirical approach, necessitated by the relative immaturity of alloy theory and modeling capability.

Today the situation is different. Alloy theory is rather more advanced; modeling methods are available on different lengthscales: the electronic, atomistic, microscopic and mesoscopic. Databases of critical parameters are widely available, for example based upon CALPHAD techniques, which whilst not yet totally accurate are becoming of increasing usefulness. Computational resources are rather cheap and plentiful. But the above does not necessarily mean that modeling approaches have as yet superceded the empirical route, or that they ever will completely.

In this paper, a modeling-based approach termed 'Alloys-byDesign' (ABD) [1] is proposed for the isolation of new grades of nickel-based superalloys, circumventing the traditional empiricism. The method combines computational thermodynamics with submodels which estimate design relevant material properties. The sub-models - referred to as merit indices - are physically based and include properties such as creep resistance [1] and yield stress [2], see [1-3] for a more detailed description of the merit indices included. The ABD approach has been used to isolate compositions of both single crystal and polycrystalline nickel-based superalloys for turbine blade and disc applications respectively.

\section{Description of Alloys-By-Design Method}

Typically, superalloys contain as many as ten different alloying elements, to confer the desired combination of properties [4]. Commonly Cr, Co, Al, Ta, Ti, Nb, Mo, W are present; sometimes $\mathrm{Re}$ and $\mathrm{Ru}$ are also present in the case of single crystal alloys. To provide grain boundary strengthening $\mathrm{C}, \mathrm{B}$ and $\mathrm{Zr}$ are added in the case of polycrystalline alloys.

The large number of possible alloying elements and their considerable solubility in nickel mean that the extent of the possible alloy design space is very considerable. Moreover, the contributions made by each element to the microstructure and properties are not independent of each other, so that alloying alters the balance of properties in a subtle way which is difficult - maybe impossible - to judge by rules-of-thumb. This situation has contributed to the present state-of-the-art in which existing alloy compositions have been chosen empirically, for example using statistical analysis of experimental data. Thus considerable use has been made of trial-and-error based testing, and ranking of alloy performance on the basis of measured rather than predicted behavior. The ABD approach - involving large-scale computational calculations to systematically search a broad compositional range - provides a potential solution to this problem.

Description of Alloy Isolation Procedure: The algorithm used is illustrated schematically in Figure 1. It relies upon a series of procedural steps represented by the boxes linked by arrows. The important, overarching strategy is to estimate the compositiondependence of the mechanical behavior and environmental performance. In this sense it relies upon brute, computational-force. Required in practice - at minimum - are many tens of thousands of calculations.

The first step therefore - see Figure 1 - is the definition of an elemental list and associated upper and lower compositional limits for each one, for example Table I. The second step makes use of thermodynamic calculations made using the CALPHAD method, specifically using the Thermo-Calc software package and an associated database of thermodynamic parameters, in this case the Thermotech TTNi8 database. For each trial composition, an estimate is made of the fraction and composition of the strengthening $\gamma^{\prime}$ phase at equilibrium, and the associated composition of the matrix phase. Other thermodynamic quantities such as chemical potentials - which are needed for estimation of the susceptibility to oxidation - are determined and stored at this point. It is also convenient to estimate kinetic parameters such as 


\begin{tabular}{|c|c|c|c|c|c|}
\hline \multirow{2}{*}{$\begin{array}{l}\text { Design Constraints } \\
\text { Resistance to Creep }\end{array}$} & \multirow{2}{*}{\multicolumn{2}{|c|}{ Oxidation Resistance }} & \multirow[b]{2}{*}{ Strength } & \multirow[b]{2}{*}{ Density } & \multirow[b]{2}{*}{ Cost } \\
\hline & & & & & \\
\hline & & & & Alloy Design System & tem \\
\hline $\begin{array}{l}\text { Elemental List } \\
\text { and } \\
\text { Compositional } \\
\text { Limits. }\end{array}$ & $\begin{array}{l}\text { Aluminum Activity } \\
\text { Lattice Misfit } \\
\text { Phase Fractions } \\
\text { hase Compositions } \\
\text { Driving Forces }\end{array}$ & $\begin{array}{l}\text { Precipitate } \\
\text { Fraction and } \\
\text { Spacing; } \\
\text { Permissible } \\
\text { instability level }\end{array}$ & $\begin{array}{c}\text { Trade-off } \\
\text { diagrams } \\
\text { Histograms } \\
\text { Scatter Plots }\end{array}$ & $\begin{array}{l}\text { Ranking } \\
\text { Sorting } \\
\text { Checking } \\
\text { Rationalization }\end{array}$ & $\begin{array}{c}\text { Buy in } \\
\text { from } \\
\text { design team }\end{array}$ \\
\hline $\begin{array}{l}\text { Define Alloy } \\
\text { Design } \\
\text { Space }\end{array}$ & $\begin{array}{l}\text { Calculations of } \\
\text { Phase Equilibrium } \\
\text { and Transitions }\end{array}$ & $\begin{array}{c}\text { Define } \\
\text { Microstructural } \\
\text { Architecture }\end{array}$ & $\begin{array}{l}\text { Determine } \\
\text { Merit } \\
\text { Indices }\end{array}$ & $\begin{array}{c}\text { Apply } \\
\text { Design } \\
\text { Constraints }\end{array}$ & $\begin{array}{c}\text { Trial } \\
\text { Alloy } \\
\text { Space }\end{array}$ \\
\hline $\begin{array}{l}\text { Estimate of } \\
\text { Calculation } \\
\text { Time and } \\
\text { Data Storage } \\
\text { Requirements. }\end{array}$ & $\begin{array}{l}\text { Thermodynamic } \\
\text { and diffusion } \\
\text { databases. } \\
\text { Planar fault } \\
\text { energies }\end{array}$ & $\begin{array}{l}\text { Elimination of } \\
\text { unsuitable } \\
\text { compositions }\end{array}$ & $\begin{array}{c}\text { Too dense? } \\
\text { Too costly? } \\
\text { Not strong enough? } \\
\text { Oxidation resistant? } \\
\text { Eliminate compositions. }\end{array}$ & $\begin{array}{l}\text { Specification } \\
\text { too } \\
\text { tight? Then } \\
\text { relax it! }\end{array}$ & $\begin{array}{l}\text { Optimum } \\
\text { Composition }\end{array}$ \\
\hline Alloy Composition & & & & & \\
\hline $\mathrm{Cr}$ & Co & Ru & w & $\mathrm{Ta}$ & $\mathrm{Nb}$ \\
\hline
\end{tabular}

Figure 1. Procedure for the 'Alloys-by-Design' method.

diffusional mobilities at this stage, which are needed for the creep calculation. Driving forces describing phase instability - for example to the topologically close-packed (TCP) phases - are also made here.

A third stage involves the definition of the microstructural architecture which is needed, and the elimination of trial compositions which do not conform to this estimate. For example, in single crystal superalloys, the creep rupture life is maximized when the $\gamma^{\prime}$ fraction lies between $60 \%-70 \%$ [5], the performance being impaired at larger and smaller values; this estimate is made at a suitable service temperature, e.g. $900{ }^{\circ} \mathrm{C}$. The $\gamma / \gamma^{\prime}$ lattice misfit should also conform to a small value, either positive or negative, since coherency is otherwise lost; thus limits are placed on its magnitude. Rejection on the basis of unsuitable microstructural architecture is also made on the basis of susceptibility to TCP formation. The susceptibility to TCP formation may be determined by making use of the d-orbital energy levels of the alloying elements (referred as $M d$ ) to determine the total effective $\overline{M d}$ level. Values of the $M d$ parameters for each element are taken from [6]. Higher values of $\overline{M d}$ are indicative of higher probability of TCP formation. Other possible methods to determine susceptibility to TCP formation may also be considered, for example CALPHAD calculations or structure maps proposed by Seiser et al. [7].

In the fourth stage, merit indices are estimated for the remaining alloys in the dataset. The estimated cost - or density - are examples of physical properties which can be used as merit indices. Alternatively, merit indices can be defined on the basis of predicted creep performance or yield stress; these are considered in further detail below. Experience has shown that it is helpful to determine critical values of the merit indices which correspond to the wellknown alloys for which the performance is well-characterized experimentally; this provides a series of targets to which newly designed alloys can be compared.
In the fifth stage, the computed merit indices are compared with limits of behavior or properties which are unacceptable, on the basis of design constraints which should be considered to be boundary conditions to the problem. At this stage, the trial datatest will have been reduced in size quite markedly; should the specification be too tight or unrealistic, it will be very small and it may be necessary to re-visit the design specification and associated merit indices to relax them.

The final, sixth stage involves analyzing the dataset of compositions which remain. Our experience has shown that this can be done in various ways. One can sort through the database for alloys which exhibit maximal values of the merit indices - the lightest, the most creep resistant, the most oxidation resistant, the cheapest for example. Or alternatively, one can use the database to determine the relative trade-off in performance which arises from different combination of properties.

Notice in Figure 1 that in the left upper and right lower portions of Figure 1 are represented the design constraints and the chemical composition respectively. The alloy design system which is proposed describes a viable method for progressing from the former to the latter. The alloy design system solves the inverse of the usual empirical route for alloy design which proceeds from the bottom right to the top left.

\section{Applications to Superalloys for Turbine Discs}

Modeling the Composition Dependence of Strength: In the case of turbine disc alloys the tensile properties - in particular yield stress - of the material will limit operational capability. For high strength disc alloys, the vast majority of strength comes from the precipitate phase, especially in the supersolvus condition, models considering the various strengthening mechanisms in these alloys $[8,9]$ have demonstrated this. Therefore, optimizing alloy composition for maximal precipitate strengthening is a critical design consideration. 
From hardening theory a merit index for strength, $M_{\text {strength }}$, is proposed. The index considers the maximum possible precipitate strength - determined to be the point where the transition from weakly coupled to strongly coupled dislocation shearing occurs which can be approximated [2], using,

$$
M_{\text {strength }}=\bar{M} \cdot \frac{1}{2} \gamma_{\mathrm{APB}} f^{1 / 2} / b
$$

where $\bar{M}$ is the Taylor factor, $\gamma_{\mathrm{APB}}$ is the anti-phase boundary energy (APBE), $f$ is the volume fraction of $\gamma^{\prime}$ and $b$ is the Burgers vector.

The relationship between $\gamma^{\prime}$ chemistry and APBE was studied using density functional theory (DFT); a number of $\mathrm{Ni}_{3}(\mathrm{Al}, \mathrm{X})$ ternary systems were evaluated [2]. For multi-component systems, an estimate for the APBE was derived from the DFT calculations, where superposition of the effect of each ternary addition was assumed. Thus, the APBE can be estimated for multi-component systems without the need of computationally costly DFT calculations.

The strength merit index was used to rank alloy compositions based solely on their mean composition - in terms of their yield stress. The strength merit index and measured yield stress are compared in Figure 2. The values for strength merit index are substantially higher than measured values for yield stress. The overestimate is attributed the assumption of a uni-modal $\gamma^{\prime}$ distribution, where the particle radius is fixed at the point of maximum precipitate strength. Furthermore, assumptions in the calculation for APBE contribute to high values for strength merit index; the effects of temperature and defects are not considered, also synergistic interactions between different solute atoms is neglected. Scattering of the linear fit is also observed, this is expected to be due to microstructural variation, for example varying $\gamma^{\prime}$ distributions.

Galindo-Nava et al. recently proposed a new model that considers precipitate strengthening for complex, multimodal particle size distributions in nickel-based superalloys [9]. The model has been used to calculate the precipitate yield stress contribution for the alloys in Figure 2. A distribution typical of a turbine disc alloy is assumed; the tertiary $\gamma^{\prime}$ fraction is $20 \%$ with a mean radius of 15 $\mathrm{nm}$ and the secondary $\gamma^{\prime}$ fraction is $80 \%$ with a mean radius of 100 $\mathrm{nm}$. The total volume fraction of $\gamma^{\prime}$ and the APBE were modeled using the $\mathrm{ABD}$ algorithm. It is evident that consideration of the role of microstructure is important. However, the composition dependent components of the model - which are relevant to alloy design - are the same; alloy strength is altered substantially by $\gamma^{\prime}$ volume fraction and APBE.

The correlation observed between the strength merit index and experimental data confirms that it is suitable for ranking the strength of alloys based upon their mean composition. The merit index highlights that a complex relationship between alloy composition and strength exists. Both $\gamma^{\prime}$ volume fraction and APBE vary substantially with alloy composition. Clearly, optimization of this design constraint lends itself much better to computational design as opposed to empirical development.
Design of a High Strength Disc Alloy: For the design of the turbine disc alloy the compositional space listed in Table I was evaluated using the the ABD method. The design intent was to isolate a high strength alloy composition which maintained a suitable balance of other performance critical properties, including: phase stability, oxidation resistance, creep strength, density, cost and processing concerns.

Table I. Compositional space searched for the polycrystalline ABD alloy.*

\begin{tabular}{lcccccccc}
\hline Alloy (at.\%) & $\mathrm{Cr}$ & $\mathrm{Co}$ & $\mathrm{W}$ & $\mathrm{Mo}$ & $\mathrm{Al}$ & $\mathrm{Ta}$ & $\mathrm{Ti}$ & $\mathrm{Nb}$ \\
\hline Min. & 8 & 8 & 0 & 0 & 2 & 0 & 1 & 0 \\
Max. & 20 & 24 & 2 & 4 & 12 & 2 & 7 & 4 \\
\hline
\end{tabular}

${ }^{*} \mathrm{C}, \mathrm{B}$ and $\mathrm{Zr}$ levels were fixed at $0.0245,0.135$ and 0.036 ,
respectively.

The typical operational temperature of the alloy was anticipated to be $650{ }^{\circ} \mathrm{C}$; although higher temperatures are expected in the rim section of the disc during certain portions of the flight cycle. Thus, the $\mathrm{ABD}$ calculations were conducted at $650{ }^{\circ} \mathrm{C}$. To assess the microstructural architecture two separate phase equilibrium conditions were considered: (i) a two phase equilibrium $\left(\gamma / \gamma^{\prime}\right)$, (ii) a five phase equilibrium $\left(\gamma / \gamma^{\prime} / \sigma / \delta / \eta\right)$. These two conditions were used to estimate the microstructure of each alloy in the as heattreated condition and after long term thermal exposure.

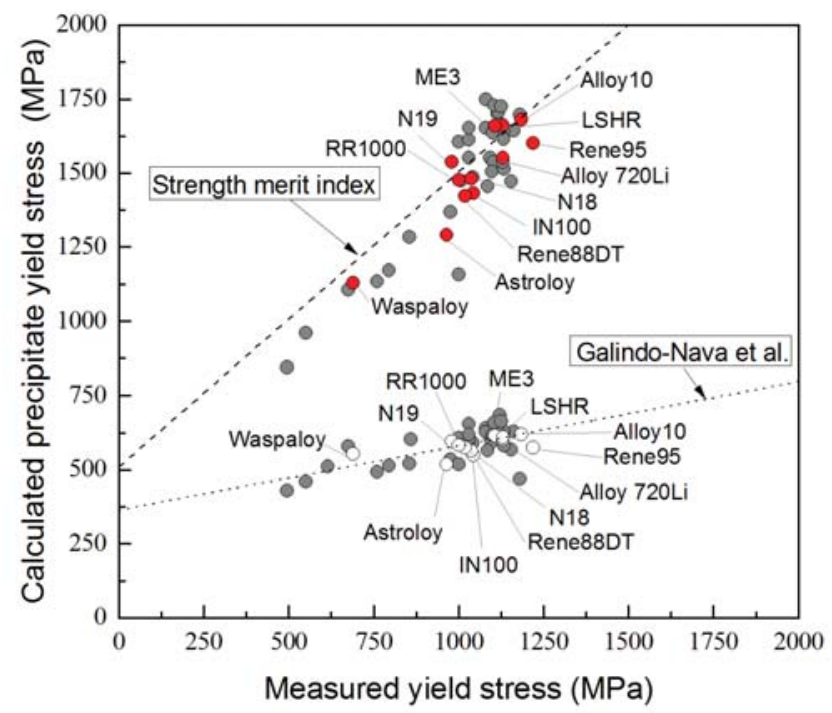

Figure 2. Measured yield stress values for a number of turbine disc alloy compositions compared with calculated precipitate yield stress, measurements and predictions at $650{ }^{\circ} \mathrm{C}$.

Contours for strength merit index are plotted as function of $\gamma^{\prime}$ volume fraction and APBE, shown in Figure 3. The position of some commonly used disc alloys are delineated, providing an overview of the current situation. The design constraint for the new alloy was a strength merit index greater than or equal to $1600 \mathrm{MPa}$. This was selected to impart the new alloy with strength equivalent to or better than current high strength disc alloys, such as ME3, LSHR and Alloy 10. The most efficient method for increasing strength is through combined increases in both $\gamma^{\prime}$ volume fraction and APBE. 
Predictions for the volume fraction of the $\gamma^{\prime}$ phase and APBE were made using the $\mathrm{ABD}$ algorithm. Thus, the composition dependence of the strength merit index could be interrogated. A scatter plotwith each datapoint representing an individual alloy within the compositional space - is superimposed upon Figure 3. Mapping of this compositional space suggests the existence of many possible alloy compositions which are stronger than currently employed alloys. Moreover, at the high levels of strength required there are many possible solutions. Thus, scope for design exists. At this point other design constraints were considered in order to isolate an alloy optimized for disc applications.

The first constraint considered was the microstructural architecture. It was critical to ensure the phase stability was achieved such that precipitation of deleterious phases including $\sigma / \delta / \eta$ was avoided. The propensity for an alloy to form $\sigma$ was considered in two ways: (i) phase equilibrium calculations, (ii) calculation of the effective $M d$ number, in this case calculated using the composition of the $\gamma$ phase estimated using the 2 phase equilibrium, $M d_{\gamma}$. A comparison of phase equilibrium calculations and the stability number $M d_{\gamma}$ across the design space was made, Figure 4. It was determined that an alloy where the stability number for the $\gamma$ composition was below 0.88 would be free from the deleterious $\sigma$ phase. To avoid instability of the $\gamma^{\prime}$ phase, modeling calculations revealed that limiting the $(\mathrm{Ti}+\mathrm{Ta}+\mathrm{Nb}) / \mathrm{Al} \leq 1$ was necessary [2]. Therefore, alloys which had an $M d_{\gamma} \geq 0.88$ and a $(\mathrm{Ti}+\mathrm{Ta}+\mathrm{Nb}) / \mathrm{Al} \geq 1$ were excluded from the design space due to an undesirable microstructure.

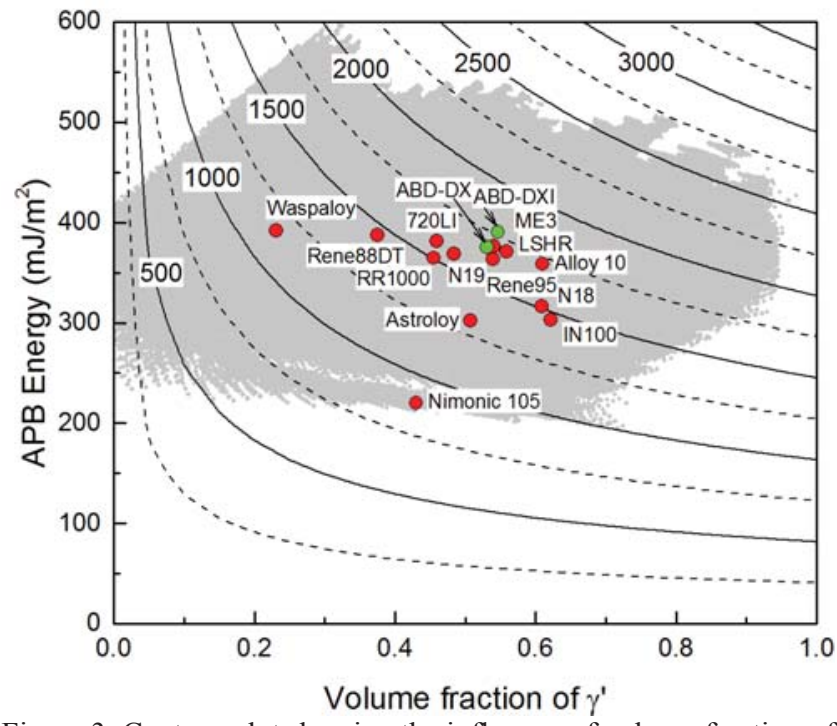

Figure 3. Contour plot showing the influence of volume fraction of $\gamma^{\prime}$ and APBE on strength merit index.

The ability to process the alloy using conventional manufacturing techniques was also of significant concern. In particular, it was required that the alloy had a sufficiently low $\gamma^{\prime}$ solvus temperature, $T_{\text {solvus, }}$ to allow for supersolvus heat-treatment, performed at temperatures above the $\gamma^{\prime}$ solvus. This heat-treatment process which dissolves intergranular primary $\gamma^{\prime}$ allowing grain growth has been found to significantly improve resistance to dwell-fatigue [10]. The $\gamma^{\prime}$ solvus was estimated using phase equilibrium calculations to determine the temperature at which complete dissolution of the $\gamma^{\prime}$ phase occurs. Alloys where $T_{\text {solvus }} \geq 1160{ }^{\circ} \mathrm{C}$ were removed from the final results.

Alloys which did not satisfy pre-defined constraints for cost and density were not considered. Limits for cost and density were placed at $15 \$ / \mathrm{lb}$ and $8.6 \mathrm{~g} / \mathrm{cm}^{3}$ respectively. This is an increase of approximately $10 \%$ in comparison to the maximal values predicted for the alloys identified on Figure 3.

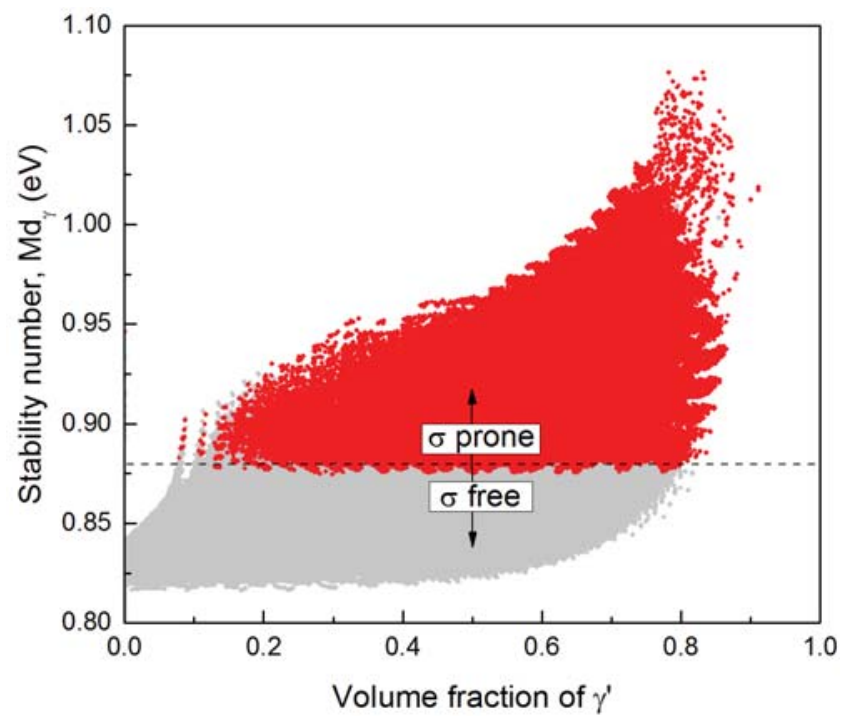

Figure 4. Scatter diagram (volume fraction of $\gamma^{\prime}$ vs. stability number) grey datapoints represent entire design space, alloys predicted to form $\sigma$ phase at $650{ }^{\circ} \mathrm{C}$ are highlighted in red.

Once the design space had been reduced - using pre-defined constraints for microstructure and merit indices - it was possible to review the remaining alloy compositions. Consideration at this point was given to: (i) Cr levels for oxidation/corrosion resistance and (ii) $\mathrm{Mo}+\mathrm{W}$ levels in order to provide creep resistance. The overarching goal was to maximize the concentration of these elements whilst maintaining strength and phase stability.

For the remaining alloy compositions, maximal values of strength merit index have been identified for each increment of $\mathrm{Cr}$ considered, Figure 5. This has been plotted at different concentrations of $\mathrm{Mo}+\mathrm{W}$. The modeling predictions show that there is a trade-off in strength-oxidation properties which must be balanced. For the new alloy it was decided that 14 at. $\%$ of $\mathrm{Cr}$ was required to impart sufficient oxidation resistance. Resistance to oxidation is assuming greater importance as rising operating temperatures are accelerating the kinetics of this reaction. Moreover, a degradation mechanism which might be termed oxidation-assisted cracking has been found to significantly reduce the safe working life of components made from these materials [11]. Based upon the constraint for $\mathrm{Cr}$ content, the level of $\mathrm{Mo}+\mathrm{W}$ was maximized, the resulting maximal concentration of $\mathrm{Mo}+\mathrm{W}$ was 2.25 at.\%. When selecting the Mo and $\mathrm{W}$ levels preference was given to $\mathrm{W}$ due to its lower rate of diffusion as this is beneficial for creep resistance. The levels of Mo and $\mathrm{W}$ were balanced in order to control alloy density. The ratio of $\mathrm{Mo} / \mathrm{W}$ is substantially reduced in comparison to many of the current disc alloys. The composition of the new alloy, named ABD-DX, is listed in Table II. 


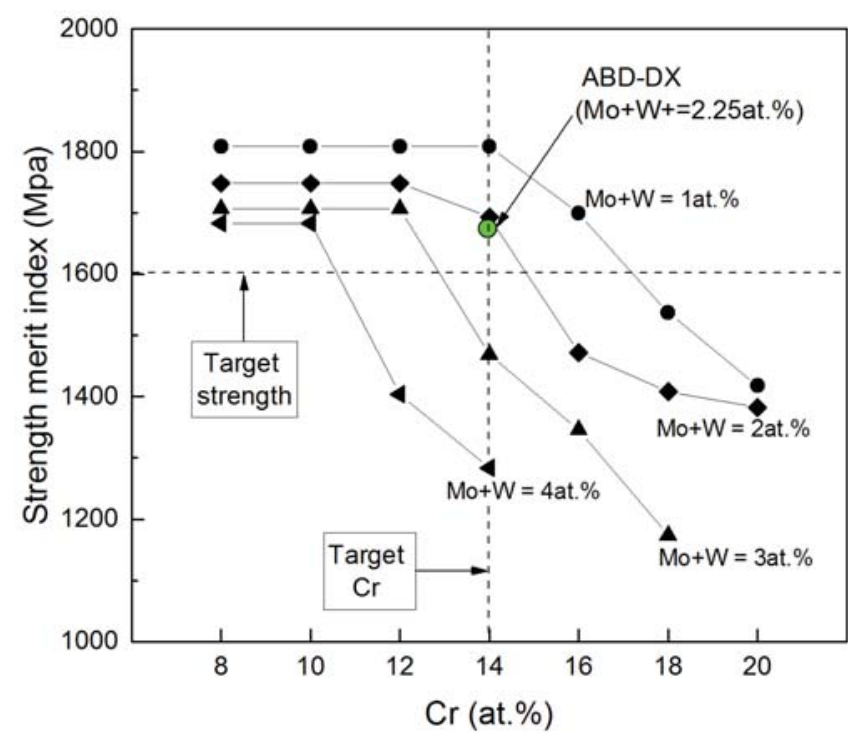

Figure 5. Variation in maximum strength merit index for alloys which meet the design constraints for microstructural stability, processing, density and cost. The variation in strength is plotted as a function of $\mathrm{Cr}$ content for different concentrations of $\mathrm{Mo}+\mathrm{W}$.

Materials Processing and Testing: The selected alloy (ABD-DX) was produced using lab-scale powder metallurgy processes. The powder was compacted using hot isostatic pressing (HIP) and then isothermally forged. The new alloy was given a super solvus heat treatment conducted at $1175{ }^{\circ} \mathrm{C}$ - approximately $20^{\circ} \mathrm{C}$ above the $\gamma^{\prime}$ solvus temperature - for 2 hours. After solution heat treatment a two-step aging process was applied $850^{\circ} \mathrm{C}$ for 2 hours, followed by a 4 hours at $800^{\circ} \mathrm{C}$.

Table II. Composition of some widely researched high strength disc alloys and the target compositions for the new ABD alloys.*

\begin{tabular}{lcccccccc}
\hline Alloy (at.\%) & Cr & Co & W & Mo & $\mathrm{Al}$ & $\mathrm{Ta}$ & $\mathrm{Ti}$ & $\mathrm{Nb}$ \\
\hline N19 & 14.8 & 12.0 & 0.9 & 2.8 & 6.2 & - & 4.4 & 0.9 \\
LSHR & 14.5 & 20.7 & 1.4 & 1.6 & 7.5 & 0.5 & 4.3 & 0.9 \\
RR1000 & 16.4 & 17.9 & - & 0.3 & 6.3 & 0.6 & 4.3 & - \\
& & & & & & & & \\
ABD-DX & 14.0 & 14.0 & 1.4 & 0.9 & 7.4 & 1.2 & 3.3 & 0.9 \\
ABD-DXI & 15.2 & 14.0 & 1.7 & 0.8 & 7.1 & 1.2 & 3.8 & 1.0 \\
\hline
\end{tabular}

*Hf, C, B and $\mathrm{Zr}$ levels not listed

Tensile testing was conducted on specimens with a gauge length of $20 \mathrm{~mm}$ and a gauge diameter of $4 \mathrm{~mm}$. Tensile properties were measured at $20,600,700$ and $800{ }^{\circ} \mathrm{C}$ using a strain rate of $0.01 / \mathrm{sec}$ until failure. The yield stress of the alloy ABD-DX is compared with currently used high strength alloys RR1000 [12], N19 [13] and LSHR [14]. These alloys were also given a super-solvus heattreatment with aging temperatures between $760-815^{\circ} \mathrm{C}$, Figure 6 .

The yield stress of alloy ABD-DX was equivalent to RR1000 across the temperature range. The ABD-DX alloy was slightly weaker than the N19 alloy up to $600{ }^{\circ} \mathrm{C}$, beyond this temperature their strength was equivalent. The alloy LSHR was stronger across the temperature range.

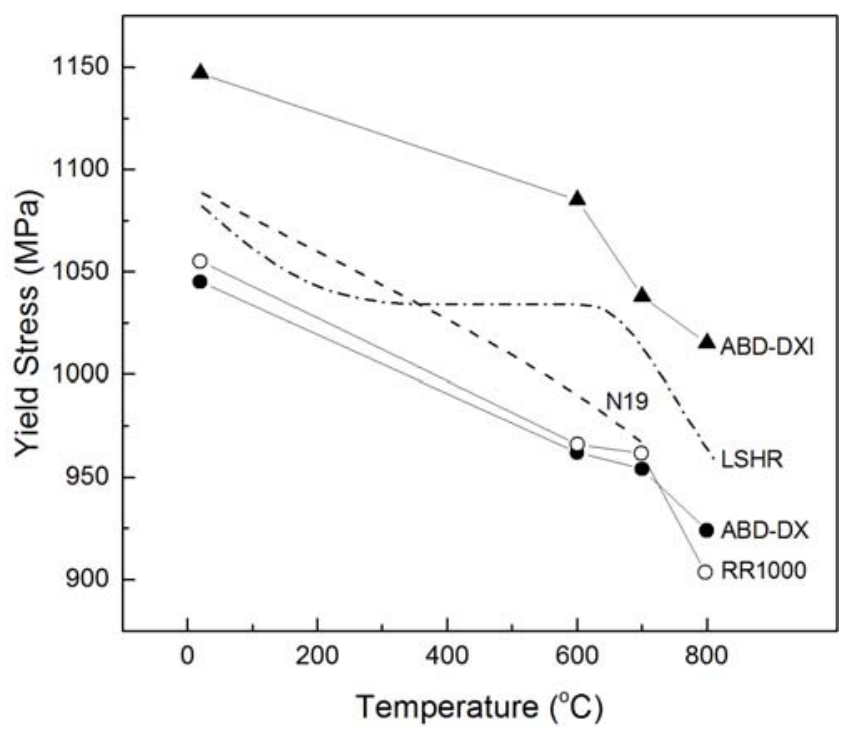

Figure 6. Experimentally measured yield stress for the newly developed disc alloys ABD-DX and ABD-DXI. Comparison is made with alloys RR1000 [12], N19 [13] and LSHR [14].

Given that the ABD-DX alloy had not attained an acceptably high yield strength a further refinement of the alloy composition was considered. To increase the strength merit index the $\mathrm{Ti} / \mathrm{Al}$ ratio was increased from 0.44 to 0.54 , raising the APBE with limited detriment to alloy density. The volume fraction of $\gamma^{\prime}$ was increased from $53 \%$ to $55 \%$. The ABD-DX alloy had showed no susceptibility to TCP phase formation. In the development of N19 experimental studies concluded that an $M d_{\gamma} \leq 0.918$ may result in an alloy free from TCP phases [15]; the new alloy was designed using this criterion. This allowed an increased concentration of $\mathrm{Cr}$ for improved oxidation resistance, as well as further additions of W for increased creep resistance. The composition of the new alloy, ABD-DXI, is listed in Table II. The new alloy underwent the same production process and heat treatment as ABD-DX.

The alloy ABD-DXI had an improvement in yield strength of approximately $100 \mathrm{MPa}$ in comparison to ABD-DX. This was consistent with the strength merit index prediction, Figure 3. Given the promising results for this alloy, as well as the scope for further refinement of alloy composition and processing, a patent application for this newly designed disc alloy has been filed [16].

\section{Applications to Single Crystal Blade Alloys}

Modeling the Composition Dependence of Creep: In the case of single crystal turbine blades, their resistance to creep deformation defines their operational limit. Constitutive physically-faithful models based upon damage mechanics link the alloy composition and microstructure-dependence of the rate of accumulation of creep strain $\dot{\varepsilon}$ when loading is uniaxial and along the $\langle 100\rangle$ crystallographic direction [17], via

$$
\begin{aligned}
\dot{\varepsilon}_{\langle 100\rangle}= & \frac{16}{\sqrt{6}} \rho_{\mathrm{m}} \emptyset_{\mathrm{p}} D_{\mathrm{eff}}\left(1-\emptyset_{\mathrm{p}}\right) \times \\
& \left(1 / \emptyset_{p}^{1 / 3}-1\right) \sinh \left\{\frac{\sigma b^{2} w}{\sqrt{6} K_{\mathrm{CF}} K T}\right\}
\end{aligned}
$$

where $\rho_{\mathrm{m}}$ is the mobile dislocation density, $\emptyset_{\mathrm{p}}$ is the volume fraction of the $\gamma^{\prime}$ phase, and $w$ is width of the matrix channels. The 


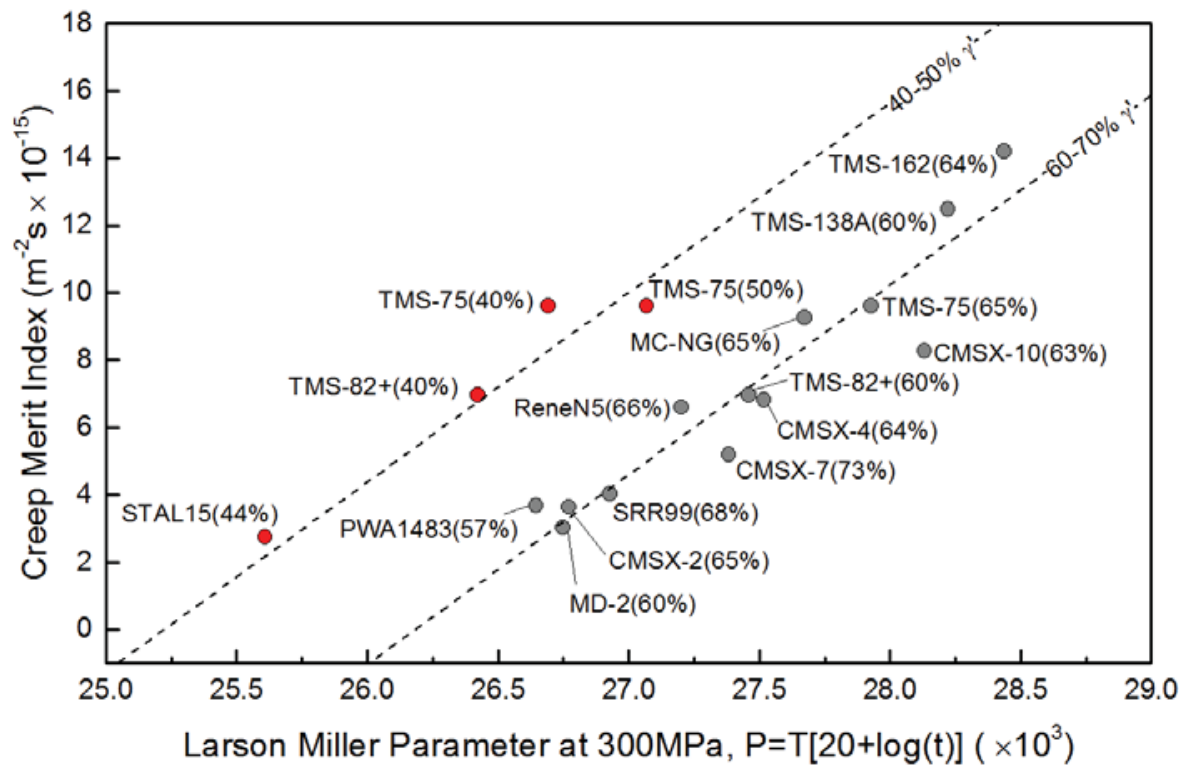

Figure 7. The Larson-Miller Parameter for single crystal superalloys at $300 \mathrm{MPa}$ compared with the predicted value for creep-merit index. The predicted volume fraction of $\gamma^{\prime}$ at $900{ }^{\circ} \mathrm{C}$ is given in brackets.

terms $\sigma$ and $\mathrm{T}$ are the applied stress and temperature respectively. The terms $b$ and $k$ are the Burgers vector and Boltzmann constant respectively. The term $K_{\mathrm{CF}}=1+2 \emptyset_{p}^{1 / 3} / 3 \sqrt{3 \pi}\left(1-\emptyset_{p}^{1 / 3}\right)$ is a constraint factor which accounts for the close proximity of the cuboidal particles in these alloys. The term $D_{\text {eff }}$ is the effective diffusivity controlling the climb processes at the particle/matrix interfaces. Note that in the above, the composition dependence

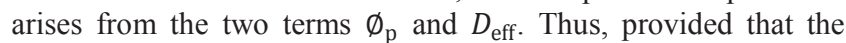
microstructural architecture is assumed constant so that $\emptyset_{\mathrm{p}}$ is fixed, any dependence upon chemical composition arises through $D_{\text {eff }}$. Therefore, a first order merit index $M_{\text {creep }}$ is employed which needs to be maximized, given by

$$
M_{\text {creep }}=\sum_{i} x_{i} / \widetilde{D_{l}}
$$

where $x_{i}$ is the atomic fraction of solute $i$ in the alloy and $\widetilde{D_{l}}$ is the appropriate interdiffusion coefficient.

Figure 7 demonstrates the predictive capability of the proposed creep-merit index. A strong correlation is observed between Larson-Miller parameter and the predicted creep merit index when the microstructural architecture is approximately constant.

Design of a Single Crystal Alloys: The ABD method was used to isolate three new single crystal superalloys. For each alloy, different design constraints were contemplated to reflect intended applications. The first alloy, ABD-1, was aimed at general gas turbine applications; in particular to (i) strike a compromise between the creep resistance and susceptibility to oxidation, and (ii) to reduce the required alloying by Re relative to commonly used alloys such as CMSX-4 due to the substantial cost of this element.

The second, termed ABD-2, was aimed at high performance applications where the very best creep resistance is needed but cost is of secondary importance. Some alloys are available for this application which contain significant concentrations of $\mathrm{Re}$ and $\mathrm{Ru}$, for example TMS-138A. However, these are prone to excessive oxidation which has restricted their implementation in practice. The challenge here is to find alloys which display sufficient oxidation resistance for practical applications.

Finally, for industrial gas turbine (IGT) applications - of the type used for electricity generation - the inclusion of expensive elements such as Re and $\mathrm{Ru}$ cannot be justified; resistance to hot corrosion and/or oxidation is of paramount importance. An alloy designated ABD-3 has been designed for these applications.

Given the varied demands for each application a broad compositional space was searched, Table III. The ABD method was used to estimate performance at $900{ }^{\circ} \mathrm{C}$. A two phase equilibrium $\left(\gamma / \gamma^{\prime}\right)$ was imposed for the CALPHAD modeling. Once the compositional space was mapped it was possible to impose design constraints, isolating alloys optimized for each service condition.

Table III. Compositional space searched for single crystal ABD alloys.

\begin{tabular}{lcccccccc}
\hline Alloy (at.\%) & $\mathrm{Cr}$ & $\mathrm{Co}$ & $\mathrm{W}$ & $\mathrm{Mo}$ & $\mathrm{Al}$ & $\mathrm{Ta}$ & $\mathrm{Re}$ & $\mathrm{Ru}$ \\
\hline Min. & 2 & 4 & 1 & 0 & 8 & 1 & 0 & 0 \\
Max. & 15 & 11 & 4 & 2 & 16 & 4 & 2 & 2 \\
\hline
\end{tabular}

For each alloy the same limits were imposed for microstructural architecture. Alloys with a $\gamma^{\prime}$ fraction between $60-70 \%$ were selected. Limits for lattice misfit, $\delta$, and stability number of the $\gamma$ phase, $M d_{\gamma}$, were also imposed. The limits imposed for the misfit $(-0.8 \% \leq \delta \leq 0.2 \%)$ and stability number $\left(M d_{\gamma} \leq 0.93\right)$ are representative of the upper and lower bounds for currently employed single crystal alloys, predicted at $900{ }^{\circ} \mathrm{C}$ using the $\mathrm{ABD}$ method.

In combination with microstructural architecture, reasonable limits for cost and density were considered. In each case a density limit of $9.0 \mathrm{~g} / \mathrm{cm}^{3}$ was imposed. Limits for cost were imposed based upon the intended use. The cost was limited to $20 \$ / 1 b, 40 \$ / 1 b$, and $320 \$ / \mathrm{lb}$ for the industrial, general purpose and the high performance applications respectively. 
Once the compositional space was reduced - by imposing the previously described limits for microstructure, cost and density the remaining alloy compositions were investigated further. In each case, a suitable balance between creep and oxidation/corrosion resistance was considered. Thus, the objective was to attain an improved balance between the creep merit index and $\mathrm{Cr}$ content with respect to benchmark alloys.

In Figure 8 the maximal value of creep merit index is plotted as a function of $\mathrm{Cr}$ content for the different levels of cost. Clearly, with increasing alloy cost substantial improvements in creep can be attained; resulting from additions of $\mathrm{Re}$ and $\mathrm{Ru}$. A trade-off between oxidation/corrosion resistance and creep is evident with creep merit index reducing as $\mathrm{Cr}$ content is increased.

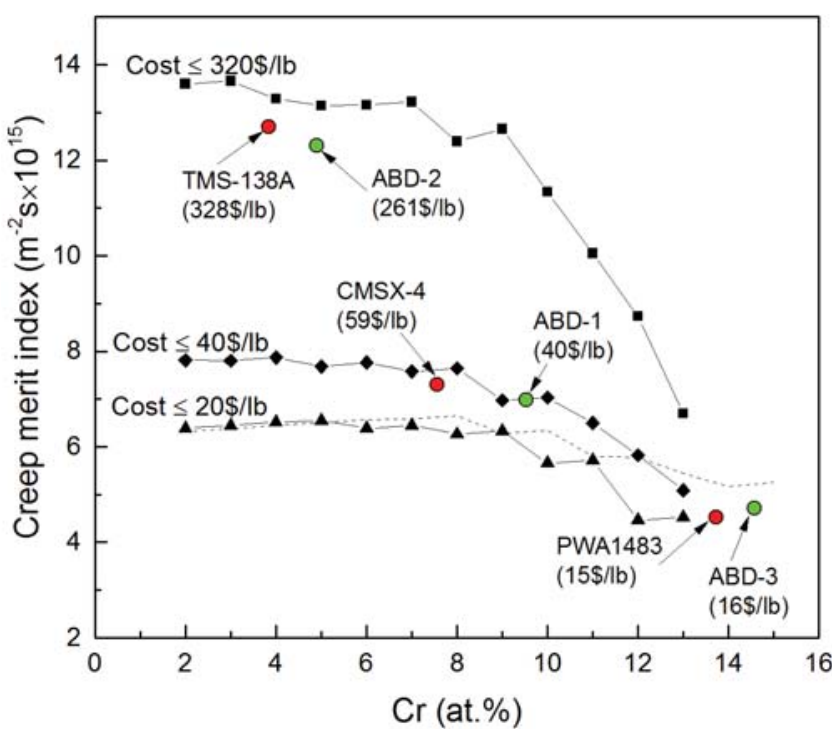

Figure 8. Variation in maximum creep merit index for alloys which meet the design constraints for, $\gamma^{\prime}$ fraction, microstructural stability and density. The variation is plotted as a function of $\mathrm{Cr}$ content for different levels of cost. The dotted line is for alloys costing less than $20 \$ / \mathrm{lb}$ containing a lower $\gamma^{\prime}$ fraction (50-60\%).

For the alloys ABD-1 and ABD-2 it was possible to isolate compositions with an improved balance of creep merit index and $\mathrm{Cr}$ content in comparison to the identified benchmark alloys CMSX-4 and TMS-138A respectively. However, in the $\gamma^{\prime}$ range of $60-70 \%$ it was not possible to have a $\mathrm{Cr}$ content greater than 13 at.\% without going beyond the limit for stability number. For ABD3 - the (IGT) alloy - the design goal was to have $\mathrm{Cr}$ greater than that of PWA1483. To attain this the volume fraction of $\gamma^{\prime}$ in the ABD-3 alloy was reduced. The dotted line on Figure 8 represents the same design constraints as previously applied for the IGT alloy with the limit for $\gamma^{\prime}$ fraction reduced to between 50-60\%.

For each application, the alloy which had the best balance of creep and oxidation/corrosion resistance was selected from the remaining dataset. The nominal compositions of the selected alloys are presented in Table IV.
Table IV. Composition of some commonly used single crystal blade alloys and the new ABD alloys.

\begin{tabular}{lccccccccc}
\hline $\begin{array}{l}\text { Alloy } \\
\text { (at.\%) }\end{array}$ & $\mathrm{Cr}$ & $\mathrm{Co}$ & $\mathrm{W}$ & $\mathrm{Mo}$ & $\mathrm{Re}$ & $\mathrm{Ru}$ & $\mathrm{Al}$ & $\mathrm{Ta}$ & $\mathrm{Ti}$ \\
\hline CMSX-4 & 7.6 & 9.3 & 2.0 & 0.4 & 1.0 & - & 12.6 & 2.2 & 1.3 \\
TMS138A & 3.9 & 6.2 & 1.9 & 1.8 & 2.0 & 2.3 & 13.3 & 2.0 & - \\
PWA1483 & 13.8 & 9.2 & 1.2 & 1.2 & - & - & 7.8 & 1.6 & 5.2 \\
& & & & & & & & & \\
& & & & & & & & & \\
ABD-1 & 9.5 & 10.5 & 2.8 & - & 0.5 & - & 13.3 & 2.9 & - \\
ABD-2 & 4.8 & 9.5 & 2.5 & - & 1.9 & 1.6 & 14.8 & 1.9 & - \\
ABD-3 & 14.7 & 10.0 & 1.6 & - & - & - & 11.8 & 2.3 & - \\
\hline
\end{tabular}

Materials Processing and Testing: Single crystal castings of alloys ABD-1, ABD-2 and ABD-3 were prepared using investment casting methods. The casting stock for the new alloys were prepared by Ross \& Catherall in Sheffield, UK to industry consistent standards. To remove microsegregation introduced from casting and to develop appropriate precipitate morphologies, suitable heat treatments were designed. Differential Thermal Analysis (DTA) was first used to identify the heat treatment window for each new alloys. Primary heat treatments chosen were $1305^{\circ} \mathrm{C} / 6$ hours for ABD-1, $1325^{\circ} \mathrm{C} / 6$ hours for $\mathrm{ABD}-2$ and 1300 ${ }^{\circ} \mathrm{C} / 4$ hours for ABD-3, respectively. In order to reprecipitate the $\gamma^{\prime}$ phase after solution treatment, the first ageing treatment was carried out at $1120^{\circ} \mathrm{C} / 3$ hours for ABD- $1,1120^{\circ} \mathrm{C} / 2$ hours for ABD-2 and $1125^{\circ} \mathrm{C} / 1$ hour for ABD-3. A secondary ageing of $870{ }^{\circ} \mathrm{C} / 16$ hours was used in all cases.

Specimens of $20 \mathrm{~mm}$ gauge length and $4 \mathrm{~mm}$ diameter were machined from fully heat-treated single crystal bars. The orientations of specimens were shown to be within $10^{\circ}$ from the $\langle 100\rangle$ direction, using Laue analysis. Specimens for cyclic oxidation testing were prepared from fully heat-treated single crystal bars with rectilinear geometry of dimensions $20 \mathrm{~mm}$ x $10 \mathrm{~mm}$ $\mathrm{x} 1 \mathrm{~mm}$. Prior to testing, the surfaces were finished with 1200 grade grit paper, polished and then cleaned in acetone in an ultrasonic bath. To assess the oxidation resistance, cyclic oxidation tests were carried out at $1000^{\circ} \mathrm{C}$ using 2 hour cycles up to 50 hours.

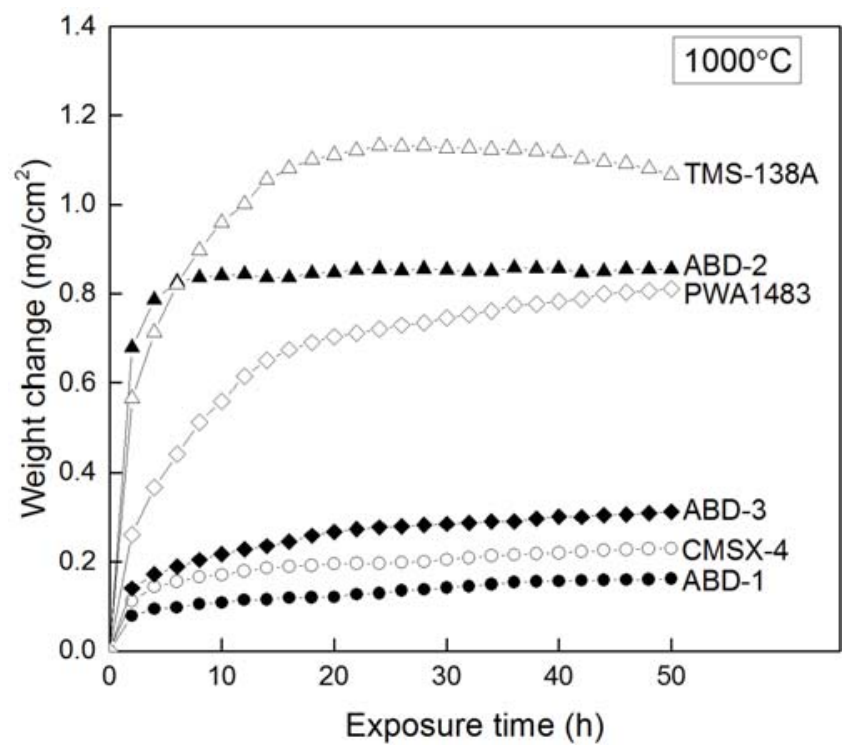

Figure 9. Weight change of $\mathrm{ABD}$ alloys during cyclic oxidation in air at $1000{ }^{\circ} \mathrm{C}$ 
Cyclic oxidation data is presented in Figure 9 for each of the ABD alloys. The oxidation behavior for the new alloys is compared with PWA1483, CMSX-4 and TMS-138A, measurements for all six alloys were conducted under the same conditions. At $1000{ }^{\circ} \mathrm{C}$, the ABD alloys exhibit better oxidation resistance than the respective benchmark alloys. ABD-1 exhibits the best oxidation behavior out of the newly design alloys, followed by ABD-3 and ABD-2.

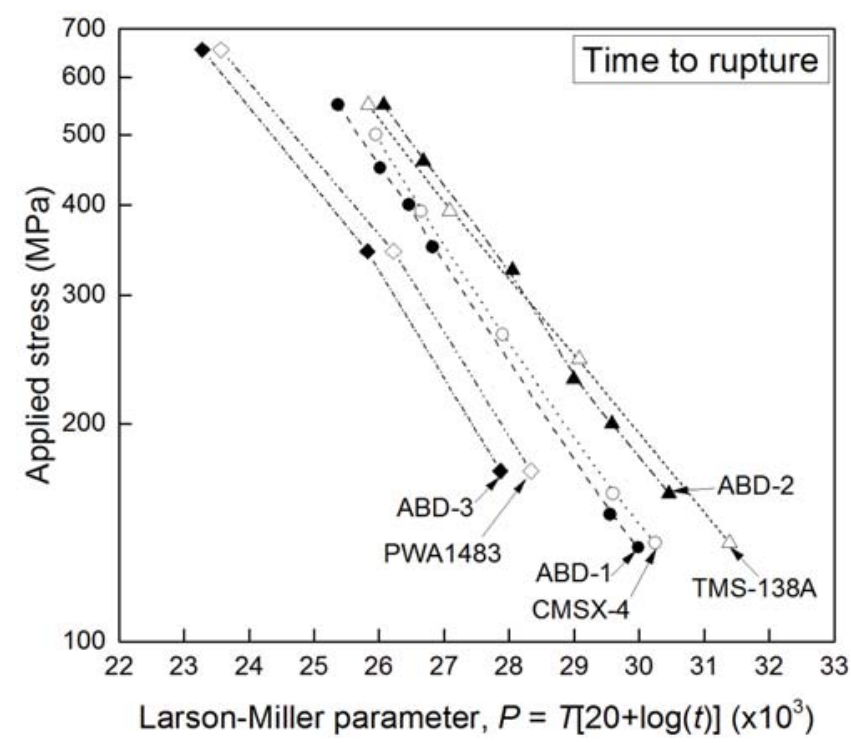

Figure 10. Larson-Miller curves for newly designed single crystal alloys.

The creep performance for the new alloys is presented using a Larson-Miller diagram, Figure 10. The creep behavior for CMSX4, TMS-138A and PWA1484 - taken from various sources [18-20] - is included for comparison. The creep performance of ABD-1 is found to be comparable to CMSX-4 for the stress range beyond 400 $\mathrm{MPa}$ but is somewhat inferior at the lower stress range when testing times are generally longer. One explanation is that the alloy is metallurgically unstable, despite being designed to be otherwise.

ABD-2 exhibits better creep resistance than alloy TMS-138A within the higher stress range. However, the formation of deleterious phases again becomes important in the low stress/high temperature regime where $\mathrm{ABD}-2$ is somewhat inferior. The findings for both $\mathrm{ABD}-1$ and $\mathrm{ABD}-2$, taken together, suggest that a stricter limit should be imposed for stability number to avoid TCP phase formation. However, it is expected that tighter tolerances for phase stability may increase the trade-off between oxidation and creep resistance.

Concerning the IGT alloy ABD-3, its creep properties are not quite as good as PWA1483 which of course does not display such good environmental resistance. It shows considerable promise for IGT applications. Patent application have now been submitted for these three newly designed single crystal alloys [21-23].

\section{Summary \& Conclusions}

In this paper, an 'Alloys-by-Design' approach which is suitable for the optimization of the compositions of nickel-based superalloys is presented. Its overarching characteristics are: (i) the mapping of a wide ranging composition space to identify a limited number of compositions predicted to have optimized microstructural architecture; (ii) use of physically-based microstructure/property models - together with density and cost estimates - which are sensitive to both microstructure and composition; (iii) models to estimate manufacturing capability, for example $\gamma^{\prime}$ solvus in disc alloys; (iv) algorithms which allow the above to be calculated and the results manipulated to allow trade-offs to be determined. There is no recourse to statistical analysis of large experimental datasets for example using neural networks.

\section{Acknowledgments}

The authors acknowledge grant (EP/D047048/1) from the Engineering and Physical Sciences Research Council (EPSRC) for all work related to the development of single crystal alloys. The financial support from the EPSRC and Rolls-Royce Strategic Partnership in Structural Metallic Systems for Advanced Gas Turbine Applications (EP/H500375/1) is acknowledged for the work on turbine disc alloy development. The authors would like to make a special thanks to Rolls-Royce plc for helpful technical discussions, provision of disc material and test results.

\section{References}

[1] R.C. Reed, T. Tao, and N. Warnken, "Alloys-by-Design: Application to nickel-based single crystal superalloys," Acta Materialia, 57 (2009), 5898-5913.

[2] D.J. Crudden, A. Mottura, N. Warnken, B. Raeisinia, and R. Reed, "Modelling of the influence of alloy composition on flow stress in high-strength nickel-based superalloys," Acta Materialia, 75 (2014), 356-370.

[3] D. J. Crudden, B. Raeisinia, N. Warnken, and R. C. Reed, "Analysis of the chemistry of nickel based turbine disk superalloys using an alloys-by-design modelling approach," Metallurgical and Materials Transactions A, 44 (2013), 2418-2430.

[4] Roger C. Reed, The Superalloys: Fundamentals and Applications. (Cambridge University Press, 2006.)

[5] T. Murakumo, T. Kobayashi, Y. Koizumi, and H. Harada, "Creep behavior of Ni-base single-crystal superalloys with various $\gamma^{\prime}$ volume fraction," Acta Materialia, 52 (2004), 3737-3744.

[6] M. Morinaga, N. Yukawa, H. Adachi, and H. Ezaki, "New phacomp and its applications to alloy design," In M. Gell, C.S. Kortovich, R.H. Bricknell, W.B. Kent, and J.F. Radavich, editors, Superalloys 1984, pages 523-532. Minerals, Metals and Materials Soc., Warrendale (PA), 1984. 
[7] B. Seiser, R. Drautz, and D.G. Pettifor, "TCP phase predictions in Ni-based superalloys: Structure maps revisited," Acta Materialia, 59 (2011), 749 - 763.

[8] R.W. Kozar, A. Suzuki, W.W. Milligan, J.J. Schirra, M.F. Savage, and T.M. Pollock, "Strengthening mechanisms in polycrystalline multimodal nickel-base superalloys," Metallurgical and Materials Transactions A, 40 (2009), 1588-1603.

[9] E.I. Galindo-Nava, L.D. Connor, and C.M.F. Rae, "On the prediction of the yield stress of unimodal and multimodal nickelbase superalloys," Acta Materialia, 98 (2015), 377-390.

[10] R.J. Mitchell, J.A. Lemsky, R. Ramanathan, H.Y. Li, K.M. Perkins, and L.D. Connor, "Process development \& microstructure $\&$ mechanical property evaluation of a dual microstructure heat treated advanced nickel disc alloy," In R.C. Reed, K.A. Green, P. Caron, T.P. Gabb, M.G. Fahrmann, and E.S. Huron, editors, Superalloys 2008, pages 347-356. Minerals, Metals and Materials Soc., Warrendale (PA), 2008.

[11] H.Y. Li, J.F. Sun, M.C. Hardy, H.E. Evans, S.J. Williams, T.J.A. Doel, and P. Bowen, "Effects of microstructure on high temperature dwell fatigue crack growth in a coarse grain PM nickel based superalloy," Acta Materialia, 90 (2015) 355-369.

[12] Private communication with Rolls-Royce plc.

[13] D. Locq, L. Naze, J. Franchet, P. Caron, A. Dumont, A. Koster, and J.Y. Guedou, "Metallurgical optimization of PM superalloy N19,” In Eurosuperalloys 2014, Giens, France, pages 6-11, 2014.

[14] T.P. Gabb, J. Gayda, J. Telesman, and P. Kantzos, “Thermal and mechanical property characterization of the advances disk alloy LSHR," Technical Report NASA/TM-2005-213645, NASA, Glenn Research Centre, 2005.

[15] J.Y. Guedou, I. Augustins-Lecallier, L. Naze, P. Caron, and D. Locq, "Development of a new fatigue and creep resistant PM nickel-base superalloy for disk applications," In R.C. Reed, K.A. Green, P. Caron, T.P. Gabb, M.G. Fahrmann, and E.S. Huron, editors, Superalloys 2008, pages 21-30. Minerals, Metals and Materials Soc., Warrendale (PA), 2008.

[16] D.J. Crudden, B. Raeisinia, M.C. Hardy, and R.C. Reed, "A nickel-based alloy," European/US Patent Application, EU14198811.3 / US14/577422, 2014.

[17] Z. Zhu, H. Basoalto, N. Warnken, and R.C. Reed, “A model for the creep deformation behaviour of nickel-based single crystal superalloys," Acta Materialia, 60 (2012), 4888-4900.

[18] A. Ma, D. Dye, and R.C. Reed, "A model for the creep deformation behaviour of single-crystal superalloy CMSX-4," Acta Materialia, 56 (2008), 1657-1670.

[19] N. Matan, D.C. Cox, P. Carter, M.A. Rist, C.M.F. Rae, and R.C. Reed, "Creep of CMSX-4 superalloy single crystals: effects of mis-orientation and temperature," Acta Materialia, 47 (1999), 1549-1563.
[20] T Hino, T Kobayashi, Y Koizumi, H Harada, and T Yamagata, "Development of a new single crystal superalloy for industrial gas turbines," In T.M. Pollock, R.D. Kissinger, R.R. Bowman, K.A. Green, M. McLean, S.L. Olson, and J.J. Schirra, editors, Superalloys 2000, pages 729-736. Minerals, Metals and Materials Soc., Warrendale (PA), 2000.

[21] R.C. Reed, D.J. Crudden, and Z. Zhu, "A low cost second generation single crystal nickel-based superalloy," British Patent Application, GB 1505653.4, 2015.

[22] R.C. Reed, D.J. Crudden, and Z. Zhu, "A fourth generation single crystal nickel-based superalloy," British Patent Application, GB 1513582.5, 2015.

[23] R.C. Reed, D.J. Crudden, and Z. Zhu, "A single crystal nickelbased superalloy designed for industrial gas turbine applications," British Patent Application, GB 1511698.1, 2015. 